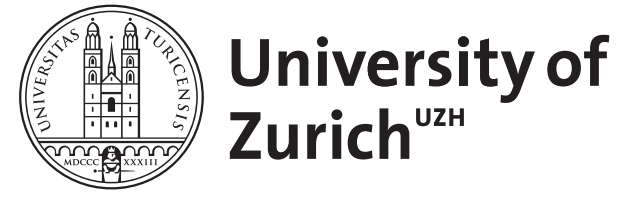

Zurich Open Repository and Archive

University of Zurich

University Library

Strickhofstrasse 39

CH-8057 Zurich

www.zora.uzh.ch

Year: 2014

\title{
Evaluating human enhancements: the importance of ideals
}

Roduit, Johann A R ; Baumann, Holger ; Heilinger, Jan-Christoph

DOI: https://doi.org/10.1007/s40592-015-0027-x

Posted at the Zurich Open Repository and Archive, University of Zurich

ZORA URL: https://doi.org/10.5167/uzh-113991

Journal Article

Published Version

Originally published at:

Roduit, Johann A R; Baumann, Holger; Heilinger, Jan-Christoph (2014). Evaluating human enhancements: the importance of ideals. Monash Bioethics Review, 32(3-4):205-216.

DOI: https://doi.org/10.1007/s40592-015-0027-x 


\title{
Evaluating human enhancements: the importance of ideals
}

\author{
Johann A. R. Roduit • Holger Baumann • \\ Jan-Christoph Heilinger
}

Published online: 5 March 2015

(c) Monash University 2015

\begin{abstract}
Is it necessary to have an ideal of perfection in mind to identify and evaluate true biotechnological human "enhancements", or can one do without? To answer this question we suggest employing the distinction between ideal and non-ideal theory, found in the debate in political philosophy about theories of justice: the distinctive views about whether one needs an idea of a perfectly just society or not when it comes to assessing the current situation and recommending steps to increase justice. In this paper we argue that evaluating human enhancements from a non-ideal perspective has some serious shortcomings, which can be avoided when endorsing an ideal approach. Our argument starts from a definition of human enhancement as improvement, which can be understood in two ways. The first approach is backward-looking and assesses improvements with regard to a status quo ante. The second, a forward-looking approach, evaluates improvements with regard to their proximity to a goal or according to an ideal. After outlining the limitations of an exclusively backward-looking view (non-ideal theory), we answer possible objections against a forward-looking view (ideal theory). Ultimately, we argue that the human enhancement debate would lack some important
\end{abstract}

J. A. R. Roduit $(\bowtie)$

Institute for Biomedical Ethics and History of Medicine, University of Zurich, Pestalozzistrasse 24, 8032 Zurich, Switzerland

e-mail: Johann.roduit@ethik.uzh.ch

J. A. R. Roduit

Oxford Uehiro Centre for Practical Ethics, University of Oxford, Suite 8, Littlegate House, 16/17 St Ebbe's Street, Oxford OX1 1PT, United Kingdom

H. Baumann

University Priority Research Program Ethics, Ethics Research Institute, University of Zurich,

Zollikerstrasse 117, Zurich 8008, Switzerland

J.-C. Heilinger

Munich Center for Ethics, University of Munich, Geschwister-Scholl-Platz 1, 80539 Munich, Germany 
moral insights if a forward-looking view of improvement is not taken into consideration.

Keywords Human enhancement · Ideal theory · Non-ideal theory · Perfection · Biomedical enhancements

\section{Ideal \& non-ideal views about human enhancement}

When it comes to making moral judgments about human enhancement interventions, a methodologically important question is whether we need ideals or assumptions about perfection in order to make these judgments, or whether it is sufficient to assess the enhanced state of a person in purely relative terms by comparing it with the former status quo ante. In this article, we argue that evaluating human enhancement exclusively from a non-ideal perspective that attempts to do without any specific ideals has some serious shortcomings. These can only be avoided when complementing it with an ideal approach. We understand "perfection" as a set of ideal human properties that allows for evaluations of enhancement interventions. Different ideas of perfection may vary in content, and these differences need to be made explicit; nevertheless, they serve the same function of making judgments and informing choices. Ideas of human perfection, hence, are substantially different but functionally similar (Roduit et al. 2013).

Our argument unfolds in three steps. (1) Starting from a definition of human enhancement as improvement, we distinguish two ways of understanding improvement. The first approach is backward-looking and assesses improvements with regard to a status quo ante. The second, a forward-looking approach, evaluates improvements with regard to their proximity to a goal or according to an ideal. (2) The assessment of relative improvements with the help of an exclusively backward-looking, comparative or non-ideal approach faces some serious limitations. It is incapable of providing a clear objective for enhancements, it is shortsighted and it only appears to be free from substantial assumptions about ideals. (3) On the other hand, there are also prominent objections against any ideal approach that spells out an ideal of human perfection. Such ideals might be thought to be insufficient, unnecessary, intolerant or inflexible. Yet, these criticisms can be moderated when the relationship between an ideal and a non-ideal approach is not understood as competitive, but as complementary.

The overall aim of our argument is to make a methodological point, not to spell out and defend any substantial account of what such an ideal would look like. This paper points out that parallels can be established between the political philosophy debate and the enhancement debate, and then analyzes what are the consequences of these analogies for the debate on human enhancement.

\subsection{Human enhancement as improvement}

Different definitions of human enhancement have been suggested in the debate. An important definition contrasts enhancements with therapeutical interventions and 
stipulates that the former are outside of the scope of the latter: enhancements are beyond therapy (Allhoff et al. 2009, 2011; President's Council on Bioethics 2003; Daniels 2000; Juengst 1998). Another noteworthy definition states that human enhancements are quantitative changes that add to an existing state of affairs; something more is added to what was already there (Chadwick 2008, 2011; Naam 2005). The final prominent definition refers to human enhancement as qualitative change. In this view, the evaluative notion of better is implied (Buchanan 2011a, b; Harris 2007; Pence 2012; Sandel 2007; Savulescu 2006). In contrast to the other definitions, understanding human enhancement as improvement provides a generally positive characterization of human enhancements and introduces a qualitative element. We take it, therefore, that to conceive of enhancements as biotechnological improvements is a particularly plausible definition, and will not discuss the first two definitions any further here. ${ }^{1}$ In contrast to the other definitions, understanding enhancement as improvement provides a generally positive characterization of human enhancements and introduces a qualitative element. In this paper, we understand human enhancement hence as an intervention in the human body by biotechnological means to improve - from some perspective, in some regard, and in a certain domainthe condition of an individual (Buchanan 2011a, Savulescu 2006).

\subsection{Two ways of looking at improvement: backward \& forward}

But what counts as an improvement? Two different ways of evaluating improvement can be distinguished. On the one hand, improvement can be evaluated in reference to a former state (status quo ante). Enhancement, on this backward-looking view, is "by definition an improvement on what went on before" (Harris 2007). This backward looking view of improvement attempts to seize the opportunities provided by biotechnological interventions to make things relatively better. This view does not require having a specific ideal or end point in mind in order to identify an improvement. Reference to a former state is already sufficient (Buchanan 2011a; Harris 2007). In this view, enhancements can be understood as "[an] improvement relative to the present state of affairs, [which] aims to remove or repair human flaws without prejudgment about what is 'ideal' or perfectly human" (Mahootian 2012, p. 143). In framing enhancement in this manner, as something not intrinsically linked to any particular ideal, this definition might also be presented as acceptable in a liberal pluralistic society (Heilinger \& Crone 2013).

However, this view invites critical questions regarding the ends of enhancement (Walker 2002; Shuman 1999; Hanson 1999; Keenan 1999; Mckenny 1999; Baertschi 2011): when attempting to improve some traits, does one aim at making them better because they are imperfections or because they are not aligned with certain ideals? And does not the concept of imperfection itself assume some conceptions of an ideal or even perfection?

According to the critics of the backward looking view, an improvement might be evaluated with regards to an end in view (Walker 2002; Keenan 1999) or a certain

\footnotetext{
${ }^{1}$ For articles dealing specifically with definitions of human enhancement, see: (Savulescu 2006; Chadwick 2008; Roduit et al. 2014).
} 
ideal (Baertschi 2009; Grunwald 2009). Such a forward-looking view is a major alternative to understanding improvements only in relation to the status quo ante, because the proximity of an enhancement intervention to an ideal is taken into account.

We can hence distinguish two ways of understanding enhancements as improvements: as departing from a status quo ante on the one hand, or as approaching a guiding ideal on the other. In the latter case it is the ideal that influences the direction of the human enhancement project, not the identification of flaws in existing circumstances as in the former case. Bernard Baertschi illustrates the forward-looking, ideal approach well:

"[N]either our desire for enhancement nor our concerns about personal identity can be properly understood without referring to an explicit or implicit ideal: the ideal of the person we want to be. This ideal is an essential part of our conception of the good life, because a good life is a life we want to live, as the person we want to be" (Baertschi 2009, p. 39)² (emphasis added).

These two different ways of evaluating enhancement as improvement have gone undifferentiated and have not been paid due attention.

\subsection{Ideal and non-ideal approaches to evaluate human enhancement}

When distinguishing a forward-looking and a backward-looking understanding of enhancement as improvement, the question thus arises as to whether these two positions are antagonistic or complementary. This discussion has some interesting similarities with the political philosophy debate about non-ideal and ideal theories of justice. Do we need to have a substantive ideal of a perfectly just society in order to identify adequate improvements of the current state, or will a non-ideal theory suffice that is able to identify relative improvements while remaining agnostic about potentially perfect end-states?

In political philosophy, Amartya Sen has recently scrutinized these two approaches (Sen 2006, 2009). Sen believes a theory to be ideal when it is not comparative, but rather absolute (Valentini 2011). Here is a working definition of a non-ideal and an ideal approach to justice in society:

- $\mathrm{X}$ is better than $\mathrm{Y}$. This comparative approach tells if one society (X) is relatively better (i.e. more just) than another one (Y). This is the non-ideal approach.

- $\mathrm{X}$ is perfect if some specific condition is met. This ideal approach outlines a perfectly just society (X). In this approach existing states of affairs are to be judged according to how close they get to the ideal (Valentini 2011).

Valentini has outlined three possible interpretations of the ideal versus non-ideal theory in political theory: (1) full compliance versus partial compliance theory; (2)

\footnotetext{
2 Translations from French are our own.
} 
utopian versus realistic theory; and (3) end-state versus transitional theory (Valentini 2012). For our purpose, we will focus on the third interpretation (endstate vs. transitional theory), because the end-state refers to an ideal or an end, while the transitional aims at comparing two alternatives in order to find the better option. ${ }^{3}$ A transitional approach does not presuppose an ideal end-state, but assumes a set of dimensions according to which relative progress can be assessed. Because of this, it is non-ideal insofar as during the ongoing transitional period all states of affairs in themselves have not reached any (indeterminate) ideal yet.

A comparative, transitional approach identifies as "better" or "worse" one out of two states of affairs that are to be compared with one another, without both an absolute positive ideal and without an idea of imperfection. It is simply a relative comparison between two entities.

Making use of these distinctions from political philosophy in the debate about human enhancement, we have two ways of approaching the possibilities of evaluating enhancement:

- The backward-looking, comparative or non-ideal approach asks, "Would it be better if human had X?" Here, two states of affairs are compared with regard to a specific dimension of human existence and the better state is identified without resorting to a fully spelled-out, complex ideal of human existence.

- The forward-looking, end-state or ideal approach asks, "What would be a perfect or ideal human being?" Here, assumptions about an ideal are the precondition for evaluating states of affairs regarding to their proximity to this ideal.

So, if we want to know how to evaluate a human enhancement intervention, is it sufficient to employ comparative, that is non-ideal criteria, or do we also need to have an ideal standard of a perfect end-point in mind? A purely backward-looking view ignores any ideals, as it finds them unnecessary and problematic for the various reasons we will outline and refute below. This view, as we will show in the next section, has serious limitations. Ultimately, we will argue that to evaluate human enhancements only from a backward-looking perspective-without taking into consideration a forward-looking approach-has some serious shortcomings. The suggested analogy between the debate in political theory and our use of it in bioethics will generate, as we will see, some interesting critique between the backward-looking and forward-looking way of looking at enhancement. In other words, the arguments used in the political debate between ideal/nonideal theory can help to illuminate the debate regarding the ethics of human enhancement.

\section{Limitations of a non-ideal approach}

Following a non-ideal approach is subject to several criticisms.

\footnotetext{
${ }^{3}$ For more details on the other view, see (Valentini 2012).
} 


\title{
2.1 Lack of an objective and shortsightedness
}

A first problem with a non-ideal approach is that it lacks a specific objective and hence is inevitably shortsighted. When speaking of a non-ideal theory of justice, John Rawls mentions that "until the ideal is identified [...] non-ideal theory lacks an objective, an aim, by reference to which its queries can be answered" (Rawls cited in Valentini 2012). In the following example, Robeyns' point fits well here and is worth quoting at length:

\begin{abstract}
"Suppose that we can represent the degree of justice of a certain situation with a number, on a scale where 100 represents the fully just social state. The initial social state $A$ has a justice value of 50. From A, we can move to either B or S, with $\mathrm{B}$ corresponding to a justice value of 70 and $\mathrm{S}$ of 55 . If we are in $\mathrm{A}$, and only compare $\mathrm{B}$ and $\mathrm{S}$, then the conclusion is easy: we have to take action so that we end up in social state B. But our possibilities for further action are not independent of this first choice. Suppose that in the best-case scenario we can move from $\mathrm{B}$ to $\mathrm{C}$, with $\mathrm{C}$ having a justice value of 80 . From $\mathrm{S}$, however, we will be able to move to $\mathrm{T}$ where we can realise a justice value of 95 . We cannot move from $\mathrm{B}$ to $\mathrm{T}$. It then becomes clear that in order to make a reasonable decision between $\mathrm{B}$ and $\mathrm{S}$, we need to know the 'paths of change' that $\mathrm{B}$ and $\mathrm{S}$ are on, and those paths are directing us towards an ideal, that is, a transcendental theory." (Robeyns 2012, pp. 160-1)
\end{abstract}

Therefore, in order to be able to fully evaluate an improvement it is essential to clarify the ideal we are aiming towards (Simmons 2010). This is where ideal theory becomes helpful as it "dictates the objective... [and] the route to that objective from whatever imperfectly just condition a society happens to occupy" (Simmons 2010, p. 12).

A similar argument to the one within the theory of justice can be made in the debate about human enhancement. Indeed, it seems difficult to know whether one is on a right path of improvement, if the end-state towards which an improvement tends remains unspecified. So, when thinking of enhancement, an important question is "towards what do we improve?" (Walker 2002) This question can be neither avoided nor answered by a purely gradual approach that allows for relative improvements in certain dimensions of human existence without spelling out an ideal, because without an ideal we cannot identify the moment when further relative changes that might appear to be as improvements cease being improvements. If qualitative judgments about improvements are based on measurable quantitative changes (as is the case in biotechnological enhancement interventions), it is clear that relative increases ad infinitum will most probably not bring about further increases in quality ad infinitum. Intelligence, empathy, physical strength etc.: relative improvements will take place only up to a certain upper limit. There is a need to spell out an ideal in order to know at which point further changes will stop being true improvements.

If no comprehensive objective of enhancement interventions is spelled out, evaluating enhancements runs the risk of being shortsighted. By this we understand judgments that identify advantages that will appear immediately so that it seems 
appropriate to speak of improvements, but fail to take into account long-term consequences that may be less advantageous and outweigh the short-term gains. It seems plausible to assume that a more specific and clearly stated goal or end-point of enhancement interventions could help avoiding such shortsightedness.

For example, if one considers becoming taller compared to a given former-state only, without any regards to an 'end-point' or without taking into consideration a forward-looking approach, becoming taller is only a quantitative change. It does not follow that such a quantitative change is an improvement. On the other hand, if one takes an ideal approach, the question of the goal and ends of human enhancement will become evident. One desires to become taller in order to become a better basketball player or to feel better in a given society, and therefore needs to fit in the "perfect range" or in the ideal range of what is the best height to play basketball or to be successful in a given society.

\subsection{The appearance of neutrality}

Non-idealists claim to remain neutral, silent or agnostic about the question of human perfection or ultimate goals of improving human beings. Instead, they want to leave it up to individuals to choose their own goals and life plans according to their individually considered preferences. This view corresponds with the dominating assumption that in liberal societies choices about individual well-being and individual goals are not a matter to be settled in general or to be prescribed to individuals.

However, it is questionable whether it is possible to uphold this appearance of neutrality about ideals, since it seems that, in some cases, the pluralist and liberal view defended by non-idealists is in itself a substantive ideal of human well-being. Being able to use the available biotechnological means to pursue human enhancement according to one's own preferences is based on the very distinctive idea of the human self as an autonomous agent that bears exclusive responsibility for one's life (Roduit et al. 2013). The emerging biotechnological means become helpful to the individual who desires to exercise mastery over her own life. So the apparently neutral, non-ideal view actually does endorse a specific ideal about autonomous agents and hence cannot claim to be neutral with regard to ideals.

Furthermore, this non-ideal view fails to acknowledge the impact societal ideas have on the shaping of individual preferences. For instance, while an individual would autonomously choose to pursue some sort of cosmetic enhancement, claiming to be free to control his life, he should be aware that different ideals of beauty have certainly influenced his so-called autonomous decision. Thereby, it becomes questionable to which degree decisions can count as "truly autonomous" at all.

Consequently, proponents of a non-ideal, backward-looking approach are unable to claim neutrality. This becomes obvious in the ethical evaluations that are made on these grounds: It has been argued that as humans we have a moral obligation to enhance our children by utilizing technological advancements in order to allow them to overcome imperfections and to fully realize what counts as valuable (Harris 2007). While claiming to be neutral at first, in order to allow individuals to make up 
their own mind about perfection, this view may even end up claiming that such or such enhancement is mandatory. However, to impose a given enhancement on someone is totally contrary to allowing individuals to make autonomous choices. Here, certain perfectionist assumptions are implicitly used. The debate of human enhancement would gain clarity by making those assumptions explicit.

Perfectionist elements hence are implicit also in the non-ideal approach to evaluating enhancements. It is advisable to tackle the question of ideals directly, since even accounts that claim not to refer to any ideals contain them implicitly.

\section{Defending an ideal approach}

In this methodological paper, we do not aim to spell out a substantive account of an ideal that should guide evaluations of human enhancement interventions. We rather argue for the need to allow also for substantive reasoning about human ideals in order to provide-in combination with and as a complement to non-ideal considerations-a comprehensive assessment of enhancement interventions. We defend the need for an ideal approach. In order to make room for such a positive account, we will-in the following section-address and reject possible objections against the need to provide a substantive account of human perfection.

\subsection{Insufficient}

Two prominent objections have been raised against ideal theory in political philosophy, the sufficiency and the necessity argument (Sen 2006). The first claims that an ideal is incapable of determining which of two non-ideal alternatives is preferable. Having an ideal does not suffice to tell which of two possibly very different states is closer to it than the other, so that perfection does not help to make "decisive comparisons among imperfect alternatives" (Sen 2009, p. 97). Only a comparative approach, that is a non-ideal one which will weigh two options directly against one another, can do this.

Against this view it has been argued that identifying an ideal aids very much in comparing non-ideal alternatives. It is not only informative insofar as it spells out at which point one would have to end attempts to improve further, also its directive power is not to be underestimated: Knowing what would be the ideal or end-state is clearly determining the general direction in which improvements should be undertaken. Eventual cases of conflict or indeterminateness notwithstanding, knowing one's goals is essential for any meaningful and reasonable action.

With regard to the debate about human enhancement the parallel objection would be that it is not helpful to know about a perfect human being when it comes to making a choice between two alternative options both of which contains some characteristics of a perfect being but not others. Non-idealists claim that knowing about perfection does not help identifying those imperfections that are worth improving (Brock 2009; Harris 2007).

However, idealists do not have to claim that an ideal alone is sufficient to evaluate enhancements. Other normative concepts such as safety, justice, and 
autonomy will also play a role. Yet, in many cases it will be helpful and necessary to resort to an ideal to complement these ethical tools in the evaluation of HE, or so the idealist can argue. But as we have shown, both sides seem to have a point here, insofar as for a comprehensive evaluation of enhancement interventions both comparative assessment and more general assessments about the overall direction of one's ambitions play an important role.

\subsection{Unnecessary}

The second argument against ideal theory claims that an ideal is not only insufficient, but also not helpful and hence not necessary for evaluating or recommending enhancement options. What matters is to compare the alternatives and options themselves, for which the idea of a perfect but remote endpoint simply is of no relevance. Looking at obvious imperfections, diseases, and disabilities and contrasting them with relatively better alternative states will realize the aim of providing decisive evaluations.

Sen suggests an analogy: If one had to compare a painting by Picasso and a painting by van Gogh, it would not help to know that the da Vinci's Mona Lisa is the best painting in the world (Sen 2009). The heterogeneous styles, ambitions and techniques involved make it wrong to resort to a single standard of perfection. In many cases, Sen argues, the answer to the question of proximity to an ideal-if there is an ideal in the first place-is superfluous.

However, Sen's argument from analogy is misleading here. To know that the Mona Lisa is the best painting would indeed help to evaluate other paintings insofar as this knowledge helps to identify criteria for perfection like creativity, use of color, use of shade and other techniques. These criteria can be found through analyzing a perfect painting like the Mona Lisa and transferred to other paintings.

Clearly, an assessment in the light of an ideal would not have to be the only evaluative tool, but one that will play an essential role in the process of evaluation.

Similarly, in the debate about human enhancement, proponents of a backwardlooking approach claim that knowledge about ideals is not necessary to identify human imperfections and recommend corresponding interventions to overcome these limitations (Harris 2007). Yet, without having an ideal in mind, which would justify why certain human imperfections may not turn out to be desirable all things considered, even apparently uncontroversial judgments about imperfections (and corresponding advice to enhance) would be insufficiently informed. For a full assessment of enhancement options it is necessary to think about the ultimate ends aimed at, otherwise one would run the risk of going astray with regard to the general direction of development.

\subsection{Pluralism and sufficiency}

A further issue is that in a world that cherishes a plurality of values and different life-plans, single comprehensive views about ideals are met with skepticism. Standardly, at least in the diverse Western contemporary societies, there is an agreement that there is more than one ideal of a flourishing human life. Also with 
regard to the distinction between ideal and non-ideal theory in political philosophy, one could argue that there are simply several equally good opportunities to realize a just society. So, how could knowledge about an ideal help justifying evaluations in a widely pluralistic society?

Here the answer consists in not overestimating the power of an ideal approach. It is not about answering all questions only with regard to an ideal, but the ideal will play an important role-even under conditions of legitimate and desired pluralism of values-when it comes to identifying the central or core values that are necessary for living a flourishing human life. Lists of basic needs, central human capabilities or essential conditions for human well-being play this role of stipulating an ideal that fixes at least a sufficiency threshold. An influential list has been suggested by Nussbaum (2011, pp. 33-34) but also Savulescu outlines a list of such elements essential to live a good life, such as intelligence, memory, patience, etc. (Savulescu 2006). These specific qualities or capabilities will then play a central role into determining an ideal.

It may appear questionable whether stipulating sufficiency can count as an ideal or a state of perfection, but in our view it makes sense to argue that to have or to be enough can very well function as a sufficient end-point for determining human enhancement.

On this account it should become plausible that an ideal does not have to be understood as an intolerant, fixed and ultimately coercive view about a specific way of living a good life (like Harris fearing that Sandel would impose his particular world view on him, Harris 2007), but may serve the basic function of determining the basic goods that are necessary for being free to live a good life that allows for multiple individual choices and preferences.

So, contrary to the views of Harris, there is a continuous need for analyzing and evaluating the best arguments about different conceptions of the good human life. While there might be a plurality of views, it remains important to assess those views according to their underlying assumptions about what is of ultimate importance or about what should count as perfect-even more so in a pluralistic society with many competing worldviews.

\subsection{Inflexible}

A remaining issue for an ideal theory approach is that it might seem inflexible, narrow-minded and status quo biased (Valentini 2011a, b), and this objection applies both to the debate about justice and to the debate about enhancement. Because once an ideal is established we might become reluctant to modify or revise it: "We remain trapped, so to speak, in the realm of perfection" (Valentini 2011, p. 302). But contrary to the non-ideal view, the solution is not to get rid of the perfectionist notions altogether, but to evaluate different conceptions and to make sure they remain open to revision as new possibilities for improvement arise.

This, of course, is a difficult challenge that has to be addressed on a societal level. Avoiding fixations and narrow views is always needed and also the ends of human enhancement interventions should not be seen as static and eternally fixed. Even the idea of human perfection may change according to the circumstances. The 
presumed endpoint that is taken to evaluate and assess human enhancement interventions should hence be understood as an "end in view" that directs our efforts for improvements without claiming absoluteness or being the last word about the good human life.

\section{Conclusion}

The ethical debate about human enhancement focuses on the question what can count as an improvement that is from a moral point of view permitted and recommended. In this paper we discussed the role that ideas of perfection play in this debate. We have contrasted to competing views, one non-ideal, backwardlooking and comparative, the other ideal and forward-looking, that is goal oriented. We have argued for a comprehensive approach, in which both approaches play an essential role. Since particularly the ideal approach faces criticism, we have dedicated particular attention to the challenge of showing the importance of ideals of human perfection in the debate, because an exclusively non-ideal approach will have shortcomings. We have not attempted to spell out the content of an ideal that would be worth pursuing or that would allow to make justified moral evaluations of enhancement interventions. This remains a task for further research. But if we succeeded to convince the readers of the importance of a differentiated view about ideals for a comprehensive assessment of enhancement interventions, we have made our methodological point.

Acknowledgments We are grateful to Pieter Bonte, Michael Buttrey, Carina Fourie, and the anonymous referees of the Monash Bioethics Review for some helpful comments on previous drafts of this article.

Funding Notes This research was supported by the Swiss National Science Foundation (SNSF, project: 141419), the Zurich University Research Priority Program for Ethics (URPP for Ethics) and the Käthe Zingg Schwichtenberg fonds (KZS) of the Swiss Academy of Medical Sciences (SAMS).

\section{References}

Allhoff, F., P. Lin, J. Moor, and J. Weckert. 2009. Ethics of human enhancement: 25 questions \& answers. Ethics, Law, and Technology 4: 1-50.

Allhoff, F., P. Lin, and J. Steinberg. 2011. Ethics of human enhancement: an executive summary. Science and Engineering Ethics 17(2): 201-212. doi:10.1007/s11948-009-9191-9.

Baertschi, B. 2009. Devenir un être humain accompli: idéal ou cauchemar? In Enhancement Éthique et philosophie de la médecine d'amélioration, ed. J.-N. Missa \& L. Perbal. (pp. 79-95). Paris: Vrin.

Baertschi, B. 2011. L'Humanité se dit de multiples manières. Journal International de Bioéthique 22(3-4): 67-76.

Bioethics, P.C. 2003. Beyond therapy: biotechnology and the pursuit of happiness. New York: Dana Press.

Brock, D.W. 2009. Is selection of children wrong? In Human enhancement, ed. J. Savulescu, and N. Bostrom. Oxford: Oxford University Press.

Buchanan, A. 2011a. Better than human: The promise and perils of enhancing ourselves (philosophy in action). Oxford: Oxford University Press. 
Buchanan, A. 2011b. Beyond humanity?: The ethics of biomedical enhancement (Uehiro Series in Practical Ethics). Oxford: Oxford University Press.

Chadwick, R. 2008. Therapy, enhancement and improvement. In Medical enhancement and posthumanity, ed. B. Gordijn, and R. Chadwick, 25-37. New York: Springer.

Chadwick, R. 2011. Enhancements: improvements for whom? Bioethics, 25(4): ii. doi:10.1111/j.14678519.2011.01899.x.

Daniels, N. 2000. Normal functioning and the treatment-enhancement distinction. Cambridge Quarterly of Healthcare Ethics 9(03): 309-322. doi:10.1017/S0963180100903037.

Grunwald, A. 2009. Human enhancement-What does "Enhancement" mean here? Retrieved from http://www.ea-aw.org/fileadmin/downloads/Newsletter/NL_88_042009.pdf.

Hanson, M.J. 1999. Indulging anxiety: human enhancement from a Protestant perspective. Christian Bioethics 5(2): 121-138. doi:10.1076/chbi.5.2.121.3789.

Harris, J. 2007. Enhancing evolution: the ethical case for making better people. Princeton: Princenton University Press.

Heilinger, J.-C., and K. Crone. 2013. Human freedom and enhancement. Journal of Medicine, Health Care, and Philosophy 17(1): 13-21.

Juengst, E. 1998. The meaning of enhancement. In Enhancing human traits: ethical and social implications, ed. E. Parens, 29-47. Washington, DC: Georgetown University Press.

Keenan, J.F. 1999. Whose perfection is it anyway ?: A virtuous consideration of enhancement. Christian Bioethics 5(2): 104-120.

Mahootian, F. 2012. Ideals of human perfection: a comparison of sulfism and transhumanism. In Building better humans?: Refocusing the debate on transhumanism, ed. H. Tirosh-Samuelson, and K.L. Mossman. Bern: Peter Lang Pub Inc.

Mckenny, G.P. 1999. Enhancements and the quest for perfection. Christian Bioethics 5(2): 99-103. doi:10.1076/chbi.5.2.99.3790.

Naam, R. 2005. More than human: Embracing the promise of biological enhancement. New York: Broadway Books.

Nussbaum, M. 2011. Creating capabilities. The human development approach. Cambridge: Harvard University Press.

Pence, G.E. 2012. How to build a better human: An ethical blueprint. Lanham: Rowman \& Littlefield Publishers.

Robeyns, I. 2012. Are transcendental theories of justice redundant? Journal of Economic Methodology 19(2): 159-163.

Roduit, J.A.R., H. Baumann, and J.-C. Heilinger. 2013. Human enhancement and perfection. Journal of Medical Ethics 39(10): 647-650. doi:10.1136/medethics-2012-100920.

Roduit, J.A.R., V. Menuz, and H. Baumann. 2014. Human enhancement: Living up to the ideal human. In Global issues and ethical considerations in human enhancement technologies, ed. S.J. Thompson, 54-66. Hershey: IGI Global.

Sandel, M.J. 2007. The case against perfection: ethics in the age of genetic engineering. Cambridge: Belknap Press of Harvard University Press.

Savulescu, J. 2006. Justice, fairness, and enhancement. Annals of the New York Academy of Sciences 1093: 321-338.

Sen, A. 2006. What do we want from a theory of justice ? The Journal of Philosophy 103(5): 215-238.

Sen, A. 2009. The idea of justice. London: Allen Lane.

Shuman, J. 1999. Desperately seeking perfection: Christian discipleship and medical genetics. Christian Bioethics 5(2): 139-153. doi:10.1076/chbi.5.2.139.3786.

Simmons, A.J. 2010. Ideal and nonideal theory. Philosophy \& Public Affairs 38(1): 5-36. doi:10.1111/j. 1088-4963.2009.01172.x.

Valentini, L. 2011. A paradigm shift in theorizing about justice? A critique of Sen. Economics and Philosophy 27(03): 297-315. doi:10.1017/S0266267111000228.

Valentini, L. 2012. Ideal versus non-ideal theory: A conceptual map. Philosophy Compass 7(9): 654-664. doi:10.1111/j.1747-9991.2012.00500.x.

Walker, M. 2002. What is Transhumanism? Why is a Transhumanist? http://www.transhumanism.org/ index.php/th/more/298/. 